\title{
A 3 kW Bidirectional DC-DC Converter for Electric Vehicles
}

\author{
Arsalan Ansari*, Puyang Cheng* and Hee-Jun Kim ${ }^{\dagger}$
}

\begin{abstract}
A bidirectional DC-DC converter (BDC) is an indispensable electrical unit for the electric vehicles (EVs). High efficiency, high power density, isolation, light weight and reliability are all essential requirements for BDC. In this paper, a $3 \mathrm{~kW} \mathrm{BDC}$ for the battery charger of EVs is proposed. The proposed converter consists of a half-bridge structure on the primary side and an isolation transformer and a synchronous rectifier structure on the secondary side. With this topology, minimum number of switching devices are required for bidirectional power flow between the two dc buses of EVs. The easy implementation of the synchronous rectification gives advantages in terms of efficiency, cost and flexibility. The proposed BDC achieves high efficiency when operating in both modes (step-up and step-down). A $3 \mathrm{~kW}$ prototype is implemented to verify theoretical analysis and the performance of the proposed converter.
\end{abstract}

Keywords: Bidirectional DC-DC converter, Battery charger, Electric vehicles, Efficiency

\section{Introduction}

With the global energy crisis the conventional vehicles (internal combustion engines) face the increasingly serious problems of energy. In contrast, the EVs especially battery electric vehicles (BEVs) depend on variety of options for its driving power. BEVs offer the advantages of safety, silent operation and no emissions when powered by renewable energy sources such as wind or solar which are virtually emission free [1]. These vehicles can also make efficient use of energy by storing energy recovered during braking or deceleration cycle in the batteries. The storage or charging process of the battery is achieved by a BDC, which is the key block in EV energy system to link high voltage (HV) de bus and low voltage (LV) dc bus as shown in Fig. 1. This BDC should have high power density and high efficiency to meet the desired goals for EV's battery charger. When the EV is parked, the battery can be charged by the household utility outlet from the grid through the BDC. For the other case when the EV is in the driving state, the $\mathrm{BDC}$ provides the electrical power from LV battery to the motor through DC-AC inverter and also DC loads in the EV.

BDCs are broadly classified into isolated and nonisolated types. The conventional non-isolated buck/boost $\mathrm{BDC}$ cannot operate in the wide voltage conversion range [2]. The isolated BDC are preferred for EVs due to the advantages of high voltage conversion ratio and safety. Many different types of isolated BDCs [3-6] have been proposed due to these advantages, some full-bridge BDCs

$\dagger$ Corresponding Author: Dept. of Electronic Systems Engineering, Hanyang University, Korea. (hjkim@hanyang.ac.kr)

* Dept. of Electronic Systems Engineering, Hanyang University, Korea. (arsalan.07el@gmail.com, chengpuyang@outlook.com)

Received: June 9, 2015; Accepted: October 29, 2015

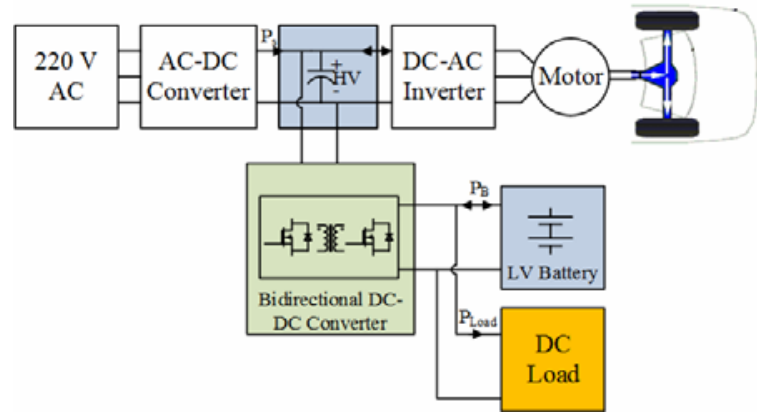

Fig. 1. The energy system of EV

[7-10] have also been proposed in recent years. However, full-bridge converters have the disadvantage of high voltage ripples if not employing an extra voltage clamping circuit [11]. By contrast, half-bridge converters [12-14] have a simple structure and a better anti-imbalance ability in the transformer. In some topologies of halfbridge converters, MOSFET body diodes are applied for synchronous rectification in both buck/boost modes [15], but high conduction losses result in low efficiency, thus limiting the use of these converters to only low power applications.

This paper describes the development of a $3 \mathrm{~kW} \mathrm{BDC}$ for EVs. The converter consists of a half-bridge topology, an isolation transformer and a synchronous rectifier. The isolation transformer provides the advantages of wide conversion range and safety, and the easy implementation of synchronous rectification offers the benefits in terms of efficiency, cost and flexibility. However, this structure has been mostly proposed for less than $1.5 \mathrm{~kW}$ application $[3,11-13,16-17]$, so the operation of more than $3 \mathrm{~kW}$ in both step-up and step-down modes has the practical significance for the EV battery charger products. 


\section{Topology Configuration and Operational Principles}

\subsection{Topology configuration}

Fig. 2 shows the circuit diagram of the proposed halfbridge BDC. The design uses a half-bridge connected with the DC power supply on the primary side and a center-tapped transformer and a synchronous rectification on the secondary side. The converter can operate in two modes, namely, step-down mode and step-up mode. All of the four switches $Q_{1}-Q_{4}$ are gated in both modes. Switch $\mathrm{Q}_{1}$ is complementary with switch $\mathrm{Q}_{4}$, and switch $\mathrm{Q}_{2}$ is complementary with switch $\mathrm{Q}_{3}$.

In the step-down mode, the primary side DC power supply $V_{H}(210-380 \mathrm{~V})$ charges the secondary side battery $V_{L}(21-29 \mathrm{~V})$, and $\mathrm{Q}_{3}$ and $\mathrm{Q}_{4}$ provide rectification. In contrast, $\mathrm{Q}_{1}$ and $\mathrm{Q}_{2}$ operate as rectifiers in the step-up

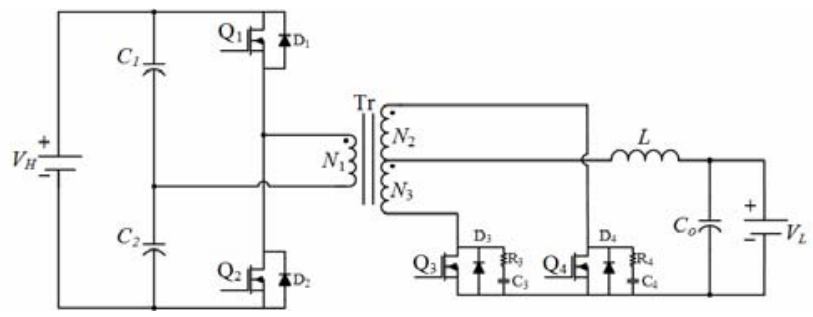

Fig. 2. Circuit diagram of the proposed converter

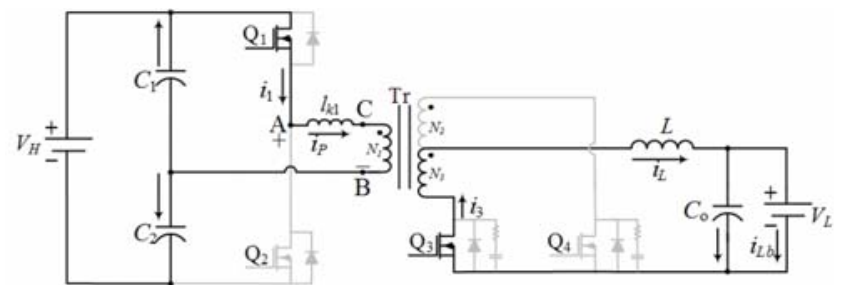

(a) Stage 1

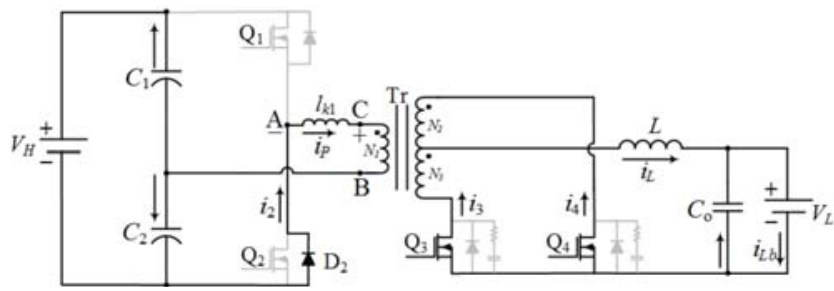

(b) Stage 2

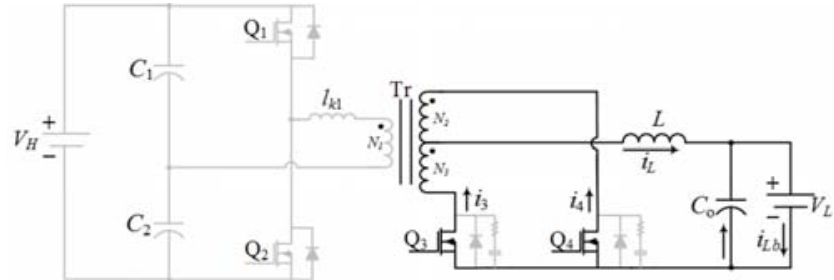

(c) Stage 3 mode when $V_{L}$ supplies the high side battery $V_{H}$. For mathematical insight into the proposed converter, some assumptions are made as: (i) the $\mathrm{ON}$-state resistance $R_{D S(O N)}$ of all switches is ignored; (ii) the capacitors $C_{1}, C_{2}$ and $C_{\mathrm{o}}$ are large enough, and the voltage across the capacitors can be taken as constant; and (iii) the capacitance of the capacitors $C_{1}$ and $C_{2}$ is equal i.e. $\mathrm{C}_{1}=\mathrm{C}_{2}=\mathrm{C}$. Thus, $V_{C 1}=V_{C 2}=V_{H} / 2$; and (iv) $\mathrm{D}_{1}-\mathrm{D}_{4}$ are the body diodes of $\mathrm{Q}_{1}-\mathrm{Q}_{4}$, and the diode forward resistance is zero.

\subsection{Operational principles of the proposed BDC}

\subsubsection{Step-down mode}

This is similar to a buck converter operational mode in which $V_{H}$ supplies $V_{L}$ with the charging current, $i_{L}$. The equivalent circuits are shown in Fig. 3 . The pulse-width modulation (PWM) technique is used to control the switches $\mathrm{Q}_{1}-\mathrm{Q}_{4}$. In both modes $\mathrm{Q}_{1}$ and $\mathrm{Q}_{2}$ are gated, with the duty cycle less than 0.5 , while the duty cycle of $\mathrm{Q}_{3}$ and $\mathrm{Q}_{4}$ is more than 0.5. Fig. 4 shows some typical waveforms for the step-down mode. The operating principles during one switching period are described as follows:

Stage $1\left[\boldsymbol{t}_{\mathbf{0}}-\boldsymbol{t}_{\mathbf{1}}\right]$ : Switch $\mathrm{Q}_{1}$ turns on and switch $\mathrm{Q}_{4}$ turns off at $t_{0}$, while switch $\mathrm{Q}_{3}$ remains on. The current flow path for this stage is shown in Fig. 3(a). In this stage $v_{\mathrm{AB}}=V_{H} / 2$, the current $i_{1}$ flows through $\mathrm{Q}_{1}$ as $i_{p}$, which is reflected from inductor current $i_{L}$. The current $i_{L}$ increases linearly and flows totally through switch $\mathrm{Q}_{3}$ to charge the battery

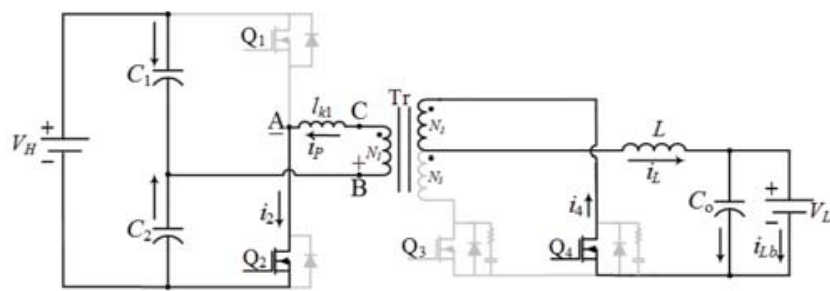

(d) Stage 4

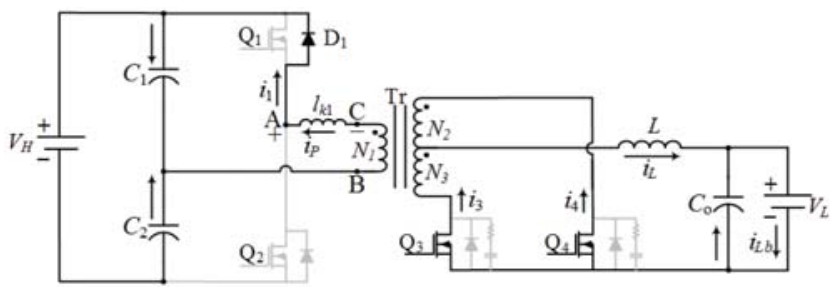

(e) Stage 5

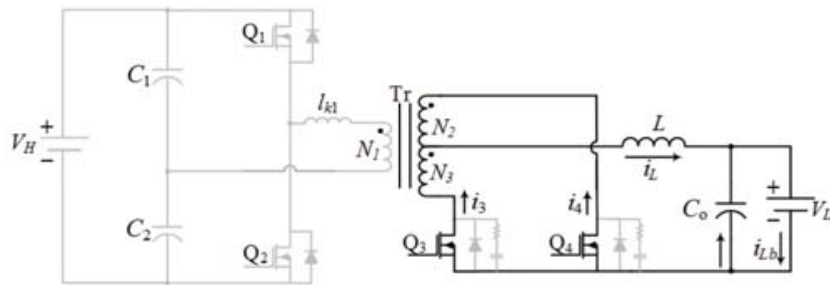

(f) Stage 6

Fig. 3. Equivalent circuits for the step-down mode 


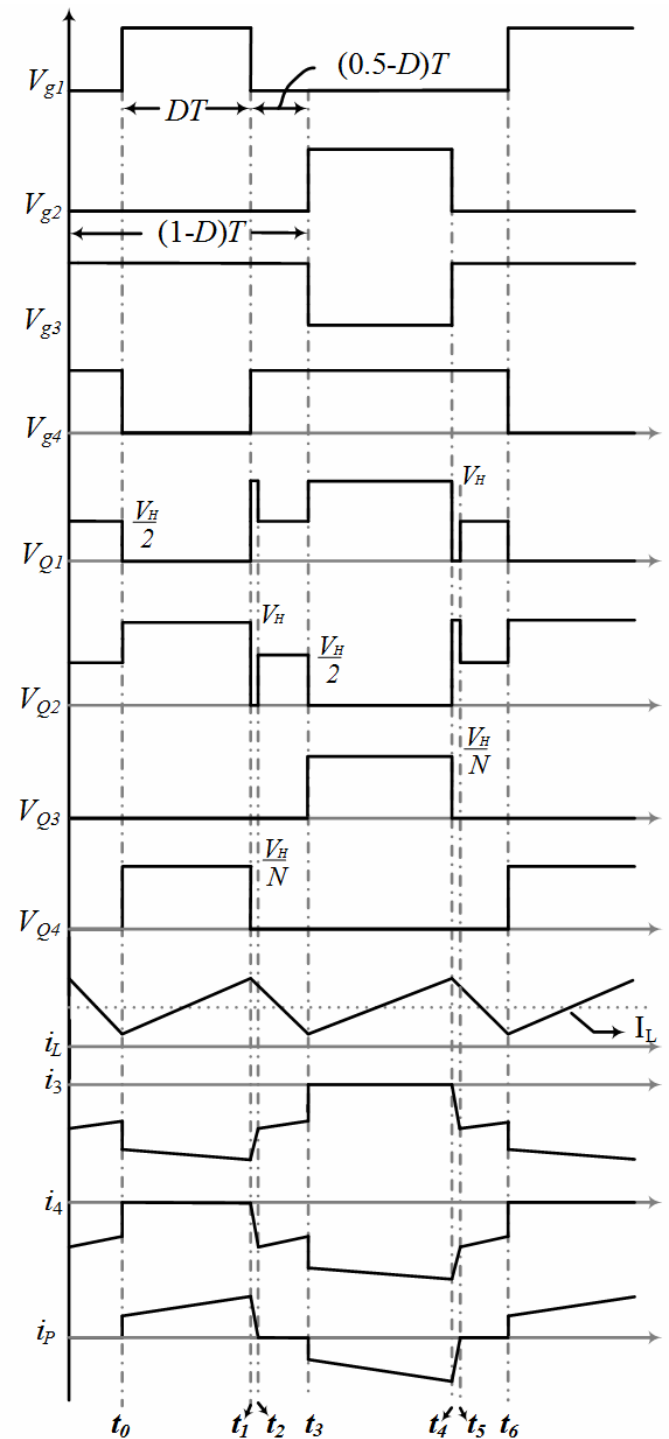

Fig. 4. Theoretical waveforms for the step-down mode

$V_{L}$.

Stage $2\left[\boldsymbol{t}_{\mathbf{1}}-\boldsymbol{t}_{\mathbf{2}}\right]$ : Switch $\mathrm{Q}_{1}$ turns off and switch $\mathrm{Q}_{4}$ turns on at $t_{1}$, while switch $\mathrm{Q}_{3}$ still remains on. Because of the transformer leakage inductance $l_{k 1}$, there is freewheeling current through $\mathrm{D}_{2}$ [Fig. 3(b)], $v_{\mathrm{CA}}=V_{H} / 2$ and $i_{p}$ decreases linearly to zero. In this stage $v_{\mathrm{A}}$ is clamped to ground so $v_{Q 2}=0$ and $v_{Q 1}=V_{H}$. Meanwhile $i_{4}$ increases and $i_{3}$ decreases linearly and at $t_{2}, i_{3}=i_{4}=i_{L} / 2$.

Stage $3\left[\boldsymbol{t}_{\mathbf{2}}-\boldsymbol{t}_{3}\right]$ : Switch $\mathrm{Q}_{1}$ and $\mathrm{Q}_{2}$ are in off state and $v_{Q 1}=v_{Q 2}=V_{H} / 2$. In this stage, $v_{\mathrm{AB}}=0$, no power is transferred to secondary side and the energy stored in the inductor $L$ charges the low side battery $V_{L}$ [Fig. 3(c)]. The current $i_{L}$ is shared equally by switches $\mathrm{Q}_{3}$ and $\mathrm{Q}_{4}$.

Stage $4\left[\boldsymbol{t}_{\mathbf{3}}-\boldsymbol{t}_{\mathbf{4}}\right]$ : Switch $\mathrm{Q}_{2}$ turns on and switch $\mathrm{Q}_{3}$ turns off at $t_{3}$, while switch $\mathrm{Q}_{4}$ remains on. The current flow path is shown in Fig. 3(d). This is a similar operation to stage $1\left[t_{0}-t_{1}\right]$, but the voltage $v_{\mathrm{AB}}=-V_{H} / 2$. The current $i_{2}$ is built as $-i_{p}$. In this stage, $\mathrm{Q}_{4}$ is conducting and $i_{4}$ increases linearly as $i_{L}$.
Stage $5\left[\boldsymbol{t}_{\mathbf{4}}-\mathbf{t}_{\mathbf{5}}\right]$ : Switch $\mathrm{Q}_{2}$ turns off and switch $\mathrm{Q}_{3}$ turns on at $t_{4}$. Switch $\mathrm{Q}_{4}$ still remains on. Because of $l_{k 1}, \mathrm{D}_{1}$ conducts and $v_{\mathrm{A}}$ is clamped as $V_{H}$, therefore $v_{Q 2}=V_{H}$ and $v_{Q 1}=0$ [Fig. 3(e)]. Meanwhile $i_{3}$ increases and $i_{4}$ decreases linearly and at $t_{5}, i_{3}=i_{4}=i_{L} / 2$.

Stage $6\left[\boldsymbol{t}_{\mathbf{5}}-\boldsymbol{t}_{\mathbf{6}}\right]$ : The operation of this stage is the same as stage 3. The current path for this stage is shown in Fig. 3(f).

\subsubsection{Step-up mode}

For the step-up mode, the equivalent circuits considering the leakage inductance of the proposed converter are shown in Fig. 5. In this operational mode, $V_{L}$ discharges to supply the primary side output voltage of $V_{H}$ with current $i_{1}$ or $i_{2}$. Because of the existence of the transformer secondary side leakage inductance $l_{k 2}$ and $l_{k 3}$, there will be current stress on $\mathrm{Q}_{3}$ and $\mathrm{Q}_{4}$. For protection of $\mathrm{Q}_{3}$ and $\mathrm{Q}_{4}$, the $\mathrm{RC}$ snubber circuit is necessary in parallel connection with $\mathrm{Q}_{3}$ and $\mathrm{Q}_{4}$. The theoretical waveforms are shown in Fig. 6, and modes of operation in one period $\left(t_{0}-t_{6}\right)$ are described as follows:

Stage $1\left[\boldsymbol{t}_{\mathbf{0}}-\boldsymbol{t}_{\mathbf{1}}\right]$ : Switch $\mathrm{Q}_{3}$ is turned on at $t_{0}$, with switch $\mathrm{Q}_{4}$ remaining on while $\mathrm{Q}_{1}$ and $\mathrm{Q}_{2}$ are in the off state. The current flow path for this stage is shown in Fig. 5(a). The secondary side of the transformer is effectively shorted, and $v_{\mathrm{AB}}=0$. Meanwhile, the energy is stored in the inductor $L$, while no energy is transferred to the primary side. In this stage, $i_{L}$ increases linearly and is divided equally between $\mathrm{Q}_{3}$ and $\mathrm{Q}_{4}$. The primary side battery $V_{H}$ is charged by the capacitors $C_{1}$ and $C_{2}$.

Stage $2\left[\boldsymbol{t}_{\mathbf{1}}-\boldsymbol{t}_{\mathbf{2}}\right]$ : Switch $\mathrm{Q}_{4}$ is turned off while switch $\mathrm{Q}_{1}$ is turned on at $t_{1}$, with switch $\mathrm{Q}_{3}$ remaining on. Because of the leakage inductance $l_{k 2}$, there is stress on $\mathrm{Q}_{4}$ and the $\mathrm{RC}$ snubber is charged by $i_{4}$ [Fig. 5(b)]. The current $i_{4}$ decreases linearly to zero and $i_{3}$ increases linearly to $i_{L}$, building $i_{1}$ as $i_{p}$ which increases linearly.

Stage $3\left[\boldsymbol{t}_{2}-\boldsymbol{t}_{3}\right]$ : In this stage $v_{\mathrm{AB}}=0$ [Fig. 5(c)], the energy stored in $L$ is transferred to the primary side, $i_{L}$ and decrease in linearity. The capacitor $\mathrm{C}_{2}$ is discharged and capacitor $\mathrm{C}_{1}$ is charged.

Stage $4\left[\boldsymbol{t}_{3}-\boldsymbol{t}_{\mathbf{4}}\right]$ : Switch $\mathrm{Q}_{4}$ is turned on, with switch $\mathrm{Q}_{3}$ remaining on while switch $\mathrm{Q}_{1}$ is turned off at $t_{3}$. This stage is similar to stage 1 in which the inductor $L$ stores energy again, and the inductor current $i_{L}$ is equally shared by switches $\mathrm{Q}_{3}$ and $\mathrm{Q}_{4}$ [Fig. 5(d)]. Capacitor $C_{1}$ and $C_{2}$ discharge to supply the primary side DC source $V_{H}$.

Stage $5\left[\boldsymbol{t}_{\mathbf{4}}-\boldsymbol{t}_{\mathbf{5}}\right]$ : At $\boldsymbol{t}_{4}$ Switch $\mathrm{Q}_{3}$ is turned off, with switch $\mathrm{Q}_{2}$ turned on and switch $\mathrm{Q}_{4}$ remaining on. Because of the leakage inductance $l_{k 3}$ [Fig. 5(e)], there is stress on $\mathrm{Q}_{3}$ and the RC snubber is charged by $i_{3}$. The current $i_{3}$ decreases linearly to zero with $i_{4}$ increasing linearly to $i_{L}$, building $i_{1}$ as $-i_{p}$.

Stage $6\left[\boldsymbol{t}_{5}-\mathbf{t}_{\mathbf{6}}\right]$ : In this stage [Fig. $\left.5(\mathrm{f})\right], i_{4}$ is built as $i_{L}$ which decreases in linearity and energy is transferred to primary side. The capacitor $C_{2}$ is charged by $i_{2}$ conducted by $\mathrm{Q}_{2}$, which decreases linearly. 


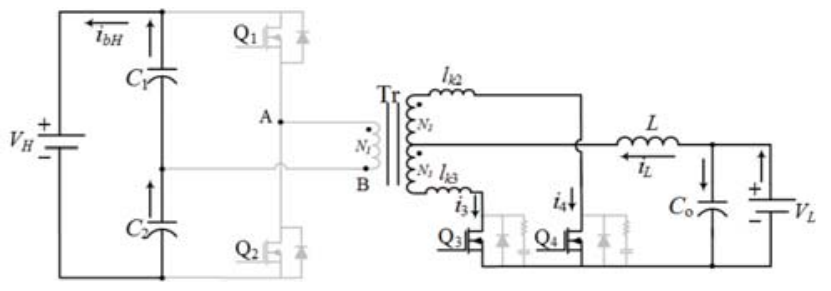

(a) Stage 1

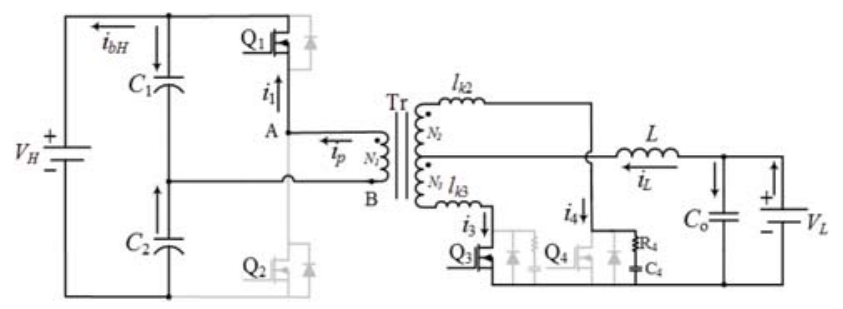

(b) Stage 2

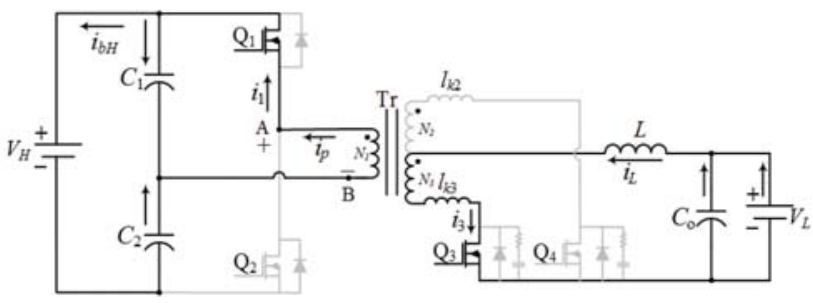

(c) Stage 3

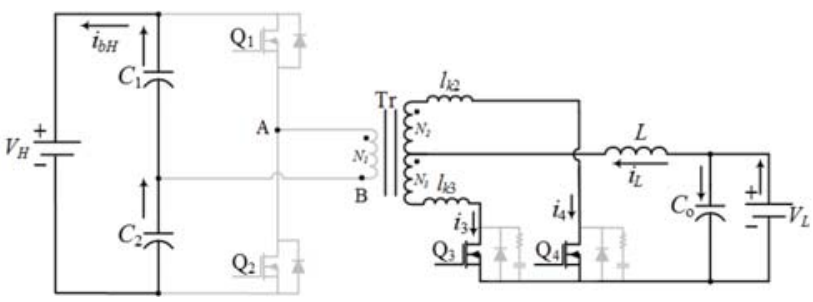

(d) Stage 4

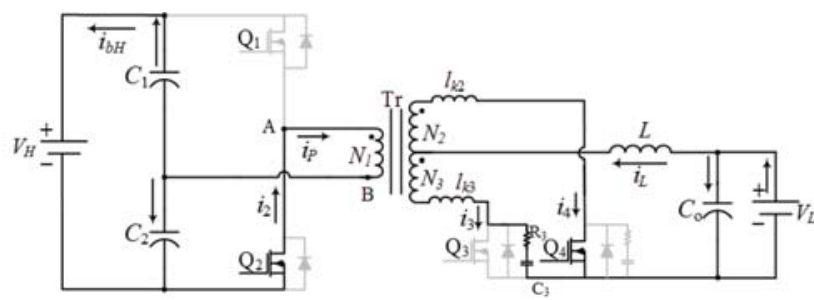

(e) Stage 5

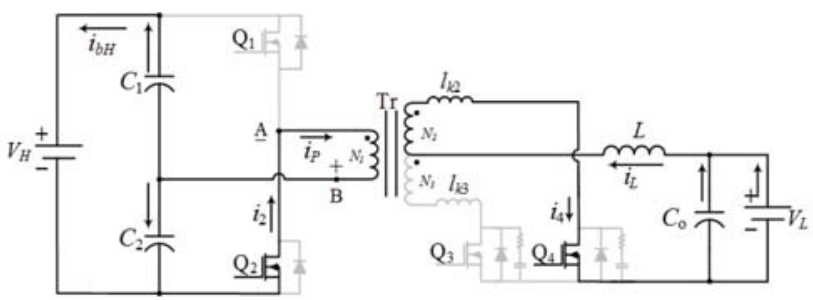

(f) Stage 6

Fig. 5. Equivalent circuits for the step-up mode

\section{Circuit Design Analysis}

The BDC operates in step-down and step-up modes. Design parameters for the step-down mode will be discussed in detail. The parameters obtained can be used for step-up mode as well. The theoretical analysis and design guidelines will be discussed in this section.

\subsection{Step-down mode}

When the number of turns on the secondary windings are equal, that is, $N_{2}=N_{3}$, then $N$ can be defined as the transformer turns ratio, as $N_{1} / N_{2}$ or $N_{1} / N_{3}$. The relationship between $V_{H}$ and $V_{L}$ is expressed as:

$$
V_{L}=\frac{D \cdot V_{H}}{N}
$$

where $D$ is the duty ratio of $\mathrm{Q}_{1}$ and $\mathrm{Q}_{2}$.

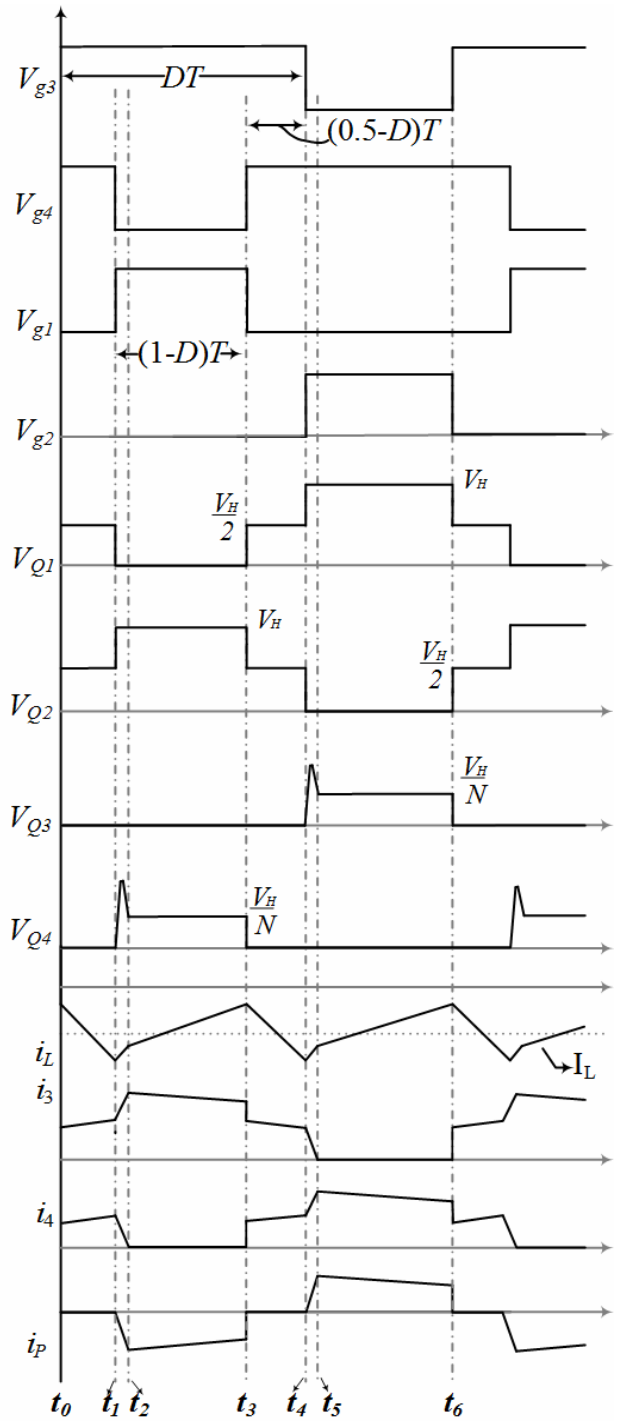

Fig. 6. Theoretical waveforms of the step-up mode 
To design the inductor $L$, the inductor current ripple $\Delta i_{L}$ and the minimum duty ratio $D_{\min }$ should be considered. The inductance $L$ can be calculated as:

$$
L \geq \frac{\left(0.5-D_{\min }\right) \cdot V_{L}}{\Delta i_{L} f_{s}}
$$

When designing output capacitor $C_{0}$, the transient overshoot should be taken into account. Because of the inductor $L$, the energy stored in $L$ will be transferred to $C_{\mathrm{o}}$ if there is a sudden change of load, causing a sudden change of $V_{C_{0}}$. According to the design specification, the overshoot voltage should be less than $3 \%$ of $V_{L}$, so that for a $50 \%$ to full load situation, $C_{\mathrm{o}}$ can be calculated as:

$$
C_{o} \geq \frac{V_{L}\left(0.5-D_{\min }\right) T_{S}^{2}}{8 L \Delta v_{C_{o}}}
$$

and for the equivalent series resistance (ESR) of $C_{0}$, the value of ESR should be limited by the following equation:

$$
R_{E S R} \leq \frac{\Delta v_{c_{o}}}{\Delta i_{C_{o}}}
$$

So several capacitors may be connected in parallel, if necessary, to meet the requirements of ESR.

The two capacitors $C_{1}$ and $C_{2}$ should be large enough to constrain the input current ripple and equally share $V_{H}$ for $\mathrm{Q}_{1}$ and $\mathrm{Q}_{2}$.

In practical applications, there are many reasons causing the voltage imbalance. A few of those are: 1) the conduction periods of the two high side switches $\mathrm{Q}_{1}$ and $\mathrm{Q}_{2}$ are not strictly equal, 2) $C_{1}$ and $C_{2}$ are charged and discharged in turns, and if the capacitance value is not big enough, there will be big voltage ripple which may cause voltage imbalance.

To avoid the voltage imbalance, it is necessary to keep the equal conduction periods for $\mathrm{Q}_{1}$ and $\mathrm{Q}_{2}$ to the maximum possibility, and it should be noted that the switch $\mathrm{Q}_{4}$ is complementary with $\mathrm{Q}_{1}$ and it is the same situation for $\mathrm{Q}_{2}$ and $\mathrm{Q}_{3}$. For $\mathrm{C}_{1}$ and $\mathrm{C}_{2}$, there is

$$
d v=i_{p} \frac{d t}{C}
$$

where $i_{p}$ is the transformer primary side current.

It can be seen that if $C$ is big enough, the ripple will be small and it will not affect the circuit operations.

The maximum voltage stress and RMS/max current ratings should be considered when selecting the switches of both sides. $\mathrm{Q}_{1}$ and $\mathrm{Q}_{2}$ have the ratings of:

$$
\mathrm{V}_{D S(\text { peak })}=\mathrm{V}_{H}
$$

$$
\begin{aligned}
I_{R M S} & =\frac{I_{L} \cdot \sqrt{2 D}}{N} \\
I_{\text {max }} & =\frac{I_{L(\max )}}{N}
\end{aligned}
$$

$\mathrm{Q}_{3}$ and $\mathrm{Q}_{4}$ have the ratings of:

$$
\begin{gathered}
V_{\text {DSpeak }}=\frac{V_{H}}{N} \\
I_{R M S}=\left[I^{2}{ }_{b} \cdot D+\left(\frac{I^{2} b}{2}\right)^{2} \cdot(1-2 D)\right]^{1 / 2} \\
I_{\text {max }}=I_{L(\text { max })}
\end{gathered}
$$

\subsection{Step-up mode}

For this mode, $V_{L}$ is the input voltage, and $V_{H}$ is output voltage. Therefore:

$$
V_{H}=\frac{N \cdot V_{L}}{1-D^{\prime}}
$$

where $D^{\prime}$ is the duty ratio of $\mathrm{Q}_{3}$ and $\mathrm{Q}_{4}$.

Because the BDC operates just as the current flows inversely, but the voltage polarity remains unchanged, so the design parameters of all components of step-down mode can be employed in the step-up mode.

\section{Experimental Results}

A $3 \mathrm{~kW}$ prototype, as shown in Fig. 7, was built and tested to evaluate the performance of the proposed BDC. The experimental parameters and circuit components are given in Table 1. The experimental waveforms of stepdown and step-up modes are shown in Fig. 8 to Fig. 13.

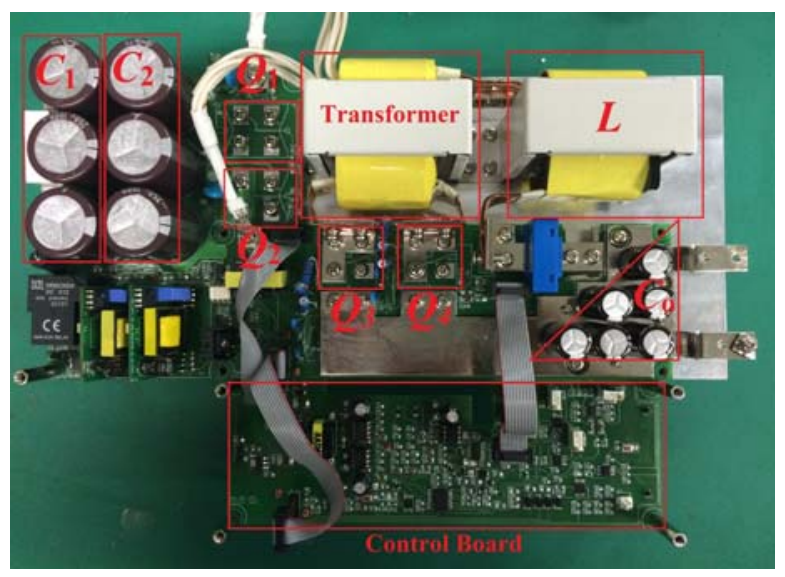

Fig. 7. Detailed photograph of the $3 \mathrm{~kW}$ proposed BDC 
Fig. 8 shows the voltage across two switches $\mathrm{Q}_{1}$ and $\mathrm{Q}_{4}$, which is $V_{Q 1}$ and $V_{Q 4}$, respectively, and the input and the output voltage $V_{H}$ of $380 \mathrm{~V}$ and $V_{L}$ of $29.6 \mathrm{~V}$ at light load. One can see that the voltage stress on switch $\mathrm{Q}_{1}$ is equal to $V_{H}$, and that on switch $\mathrm{Q}_{4}$ is equal to $V_{H} / N$. The output

Table. 1. Experimental parameters

\begin{tabular}{c|c}
\hline Parameters & Value \\
\hline$C_{1} \& C_{2}$ & $1000 \mathrm{uF} / 250 \mathrm{~V} \times 3$ in parallel \\
$C_{\mathrm{o}}$ & $1000 \mu \mathrm{F} / 50 \mathrm{~V} \times 6$ in parallel \\
$\mathrm{Q}_{1} \& \mathrm{Q}_{2}$ & IXFN60N80P \\
$\mathrm{Q}_{3} \& \mathrm{Q}_{4}$ & IXFN210N30P3 \\
$L$ & $10 \mu \mathrm{H}$ \\
Switching Frequency & $50 \mathrm{kHz}$ \\
Max: Output Power & $3 \mathrm{~kW}$ \\
$\mathrm{R}_{3}, \mathrm{R}_{4}$ & $8 \Omega$ \\
$\mathrm{C}_{3}, \mathrm{C}_{4}$ & $103 \mathrm{k} / 1 \mathrm{kV}$ \\
\hline Transformer para: & \\
\hline$N_{1}$ & 2.5 \\
$N_{2} \& N_{3}$ & 2.5 \\
$l_{k 1} / l_{m 1}$ & $28 \mu \mathrm{H} / 0.5 \mathrm{mH}=0.56 \%$ \\
$l_{k 2}$ or $l_{k 3} l_{m 2}$ or $l_{m 3}$ & $1.2 \mu \mathrm{H} / 55 \mu \mathrm{H}=2.1 \%$ \\
\hline
\end{tabular}

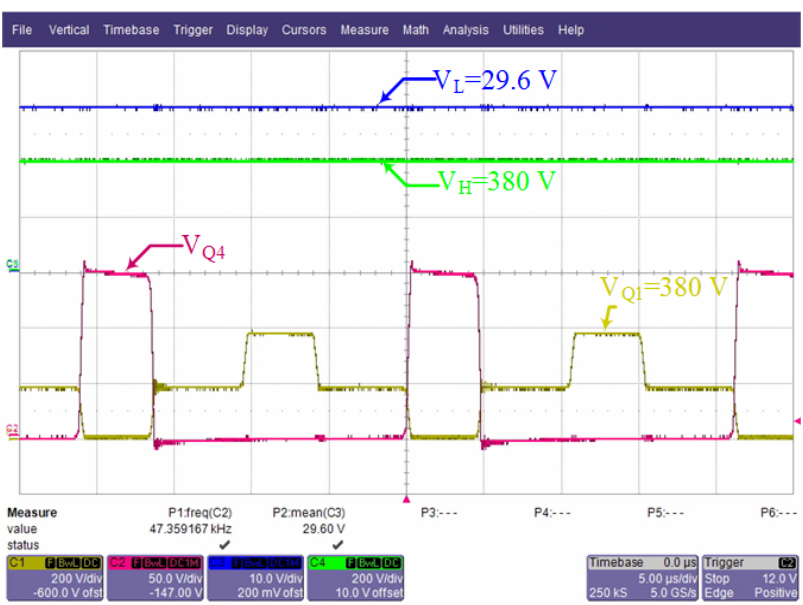

Fig. 8. Step-down mode experimental waveforms at light load

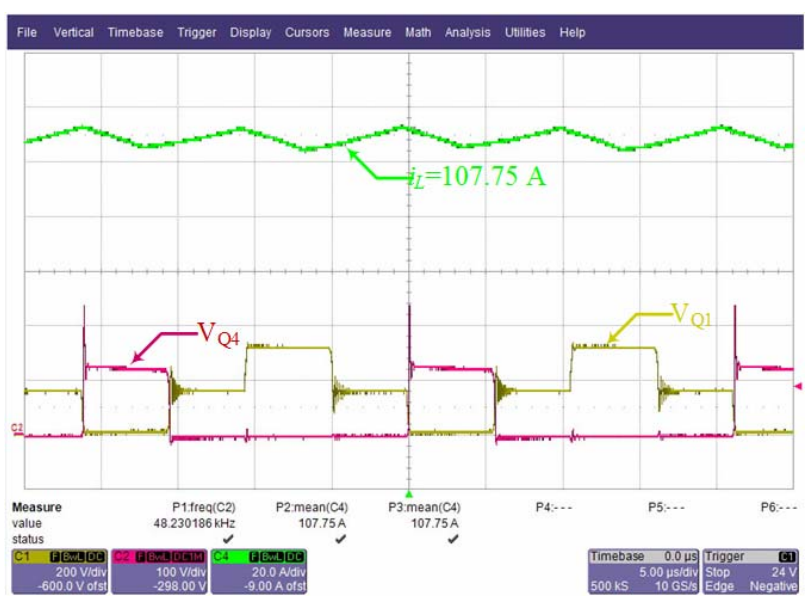

Fig. 9. Step-down mode experimental waveforms at full load voltage $V_{L}$ is well regulated at $29 \mathrm{~V}$. In this situation, the duty ratio of switches $\mathrm{Q}_{1}$ and $\mathrm{Q}_{2}$ is $23.4 \%$.

Fig. 9 shows the inductor current $i_{L}$ and the switch

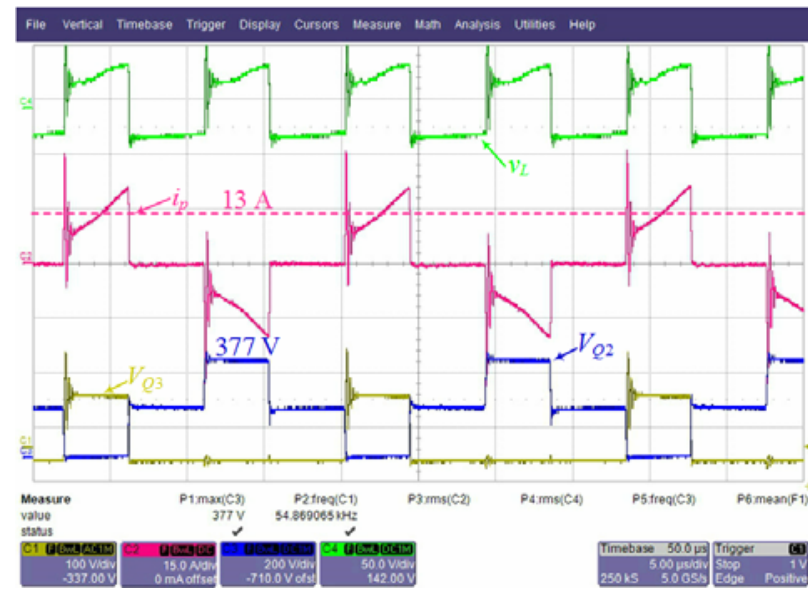

Fig. 10. Step-down mode experimental waveforms at $1 \mathrm{~kW}$

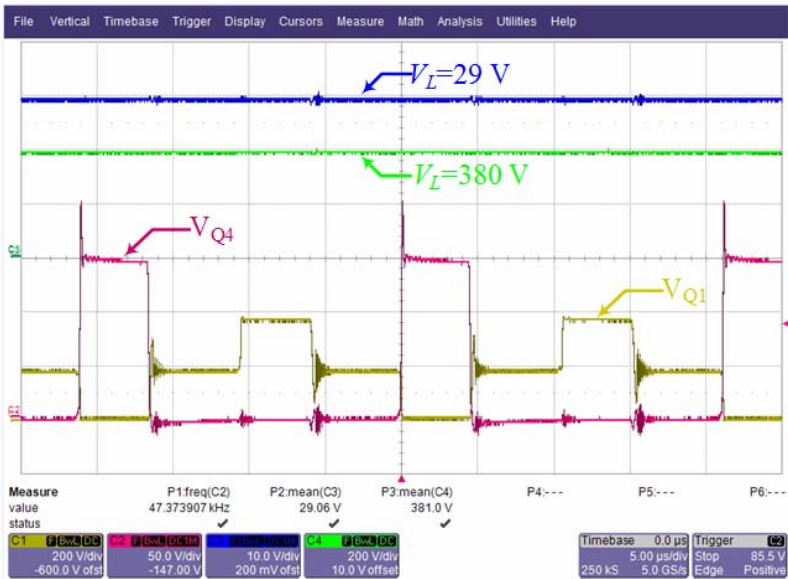

Fig. 11. Step-up mode experimental waveforms at light load

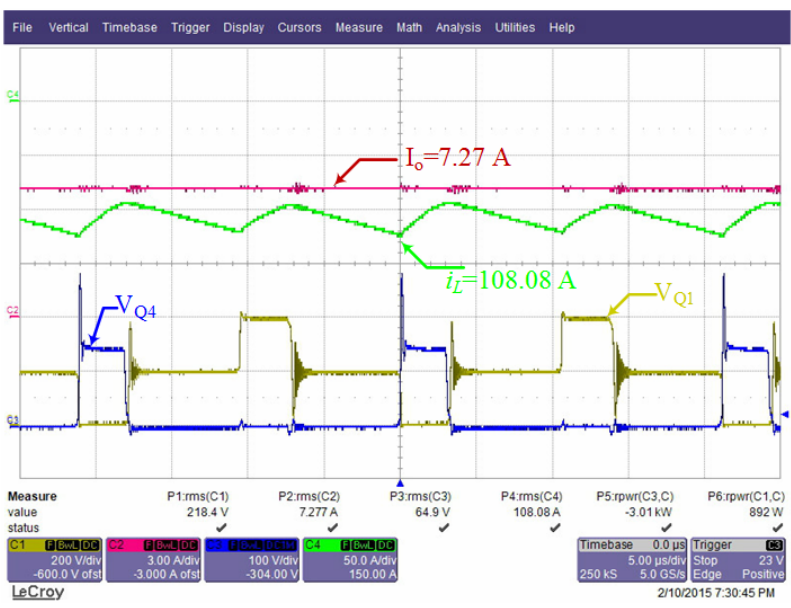

Fig. 12. Step-up mode experimental waveforms at full load 
voltages $V_{Q 1}$ and $V_{Q 4}$ at full load. It can be seen that the average output current $i_{L, A v g}$ is $107.75 \mathrm{~A}$, achieving $3.1 \mathrm{~kW}$ output power.

Fig. 10 shows the step-down $1 \mathrm{~kW}$ experimental waveforms. Channel 1 and channel 3 show the drain-to-source voltage $V_{Q 3}$ and $V_{Q 2}$. The input voltage can be seen from the maximum value of $V_{Q 2(\max )}$ as $377 \mathrm{~V}$ and the output voltage is $29 \mathrm{~V}$. In this situation the duty ratio of $\mathrm{Q}_{1}$ and $\mathrm{Q}_{2}$ is about $23.1 \%$. Channel 2 shows transformer primary side current which changes the direction accordingly when $\mathrm{Q}_{1}$ or $\mathrm{Q}_{2}$ are turned on. The average value of every conduction period is

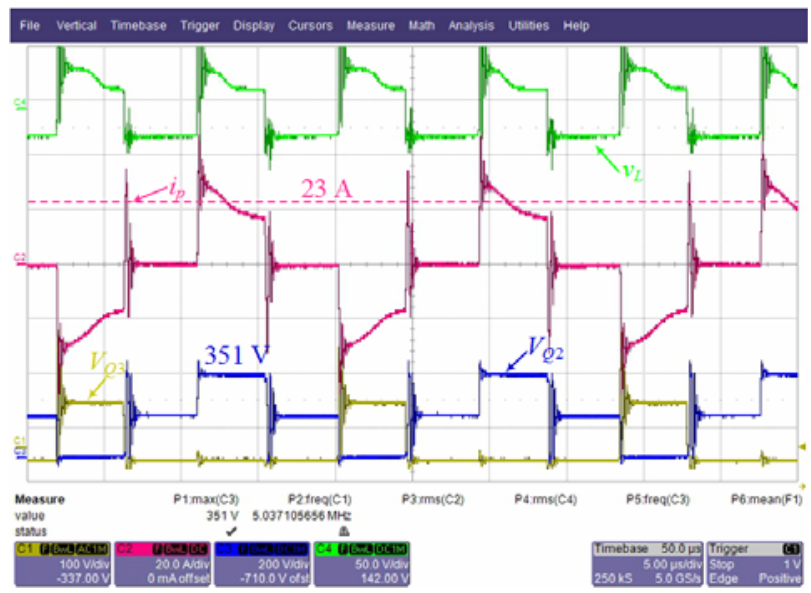

Fig. 13. Step-up mode experimental waveforms at $2 \mathrm{~kW}$

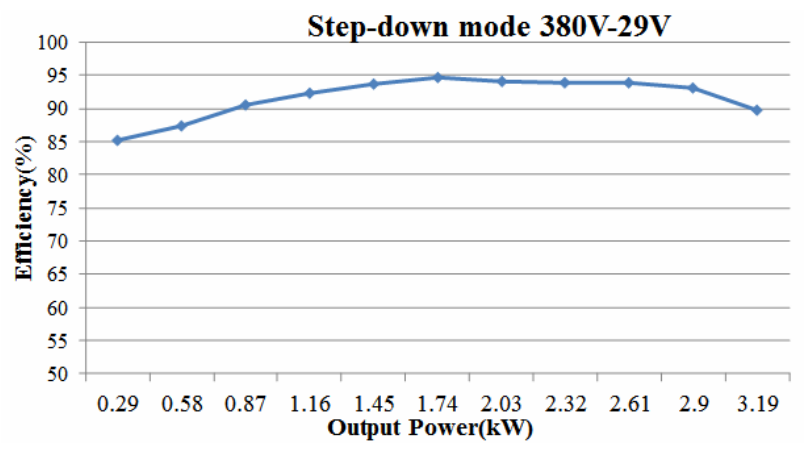

Fig. 14. System efficiency in step-down mode

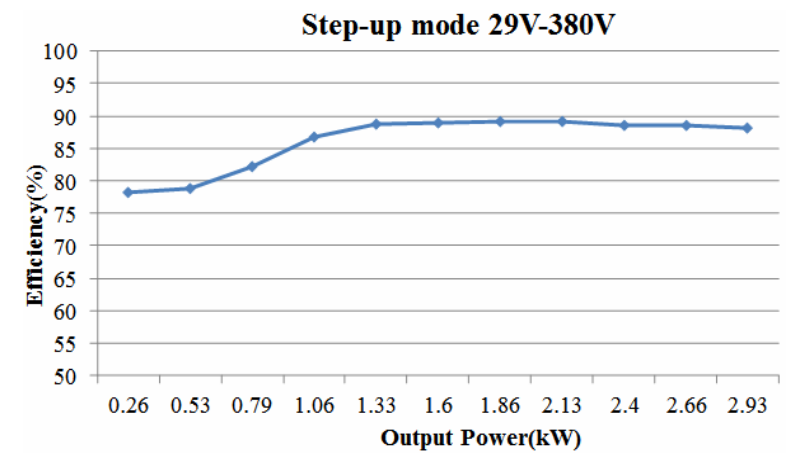

Fig. 15. System efficiency in step-up mode about 13 A. Channel 4 shows the voltage across $L$.

Fig. 11 shows $V_{Q 1}, V_{Q 4}, V_{L}$ and $V_{H}$ for the step-up mode at light loads. It should be noted that the output voltage is well regulated at $380 \mathrm{~V}$, and the maximum voltage on switch $\mathrm{Q}_{1}$ is equal to $V_{H}$ and that on switch $\mathrm{Q}_{4}$ is $V_{H} / N$. In this situation, the duty ratio of $\mathrm{Q}_{3}$ and $\mathrm{Q}_{4}$ is $77.2 \%$.

Fig. 12 shows the average input current of $-108.08 \mathrm{~A}$, output current of $7.26 \mathrm{~A}$, and the voltage across switches $\mathrm{Q}_{1}$ and $\mathrm{Q}_{4}$ at full load conditions. The input and output power obtained are $3.13 \mathrm{~kW}$ and $2.76 \mathrm{~kW}$, respectively.

Fig. 13 shows the step up mode $2 \mathrm{~kW}$ experimental waveforms. The input voltage is $29 \mathrm{~V}$ and the output voltage can be seen from $V_{Q 2(\max )}$ as $351 \mathrm{~V}$. In this situation the duty ratio of Q3 and Q4 is about $75.2 \%$. Channel 2 shows transformer primary side current $i_{P}$ with the average value of every conduction period about 23 A. Channel 4 shows the voltage across the inductor $L$.

Fig. 14 shows the measured efficiencies of the proposed BDC when it operates in step-down mode. The converter achieves efficiency of higher than $90 \%$ from $30 \%$ to full load.

Fig. 15 shows the measured efficiencies of the proposed converter when it operates in step-up mode. It can be seen that more than $88 \%$ of the efficiency is achieved from $30 \%$ to full load.

\section{Conclusion}

A $3 \mathrm{~kW}$ BDC for EVs is proposed in this paper. With a simple topology structure, the converter consists of a halfbridge on the primary side and a synchronous rectifier on the secondary side. Four switches are employed in both the step-down mode and step-up mode. The theoretical analyses have been proved by the experimental results of the $3 \mathrm{~kW}$ prototype circuit. When operating in step-down mode, an efficiency was achieved of more than $90 \%$ from $30 \%$ to the full load, while an efficiency of $88.2 \%$ is achieved at full load for the step-up mode.

\section{Acknowledgments}

This work was supported by the Human Resources Program in Energy Technology of the Korea Institute of Energy Technology Evaluation and Planning (KETEP), granted financial resources from the Ministry of Trade, Industry and Energy, Republic of Korea. (20154030200730)

This work was supported by the Energy Efficiency \& Resources Department of the Korea Institute of Energy Technology Evaluation and Planning (KETEP) and was granted financial resources from the Ministry of Trade, Industry and Energy, Republic of Korea. (20132010101950) 


\section{References}

[1] Junsung Park, and Sewan Choi, "Design and control of a bidirectional resonant DC-DC converter for automotive engine/battery hybrid power generators," IEEE Transactions on Power Electronics, vol. 29, no. 7, pp. 3748-3757, 2014.

[2] C.C. Lin, L.S. Yang and G.W. Wu, "Study of a nonisolated bidirectional DC-dc converter," IET Power Electronics, vol. 6, no. 1, pp. 30-37, 2013.

[3] Z. Zhang, O. Thomsen, and M. Andersen, "Optimal design of a push-pull-forward half-bridge (PPFHB) bidirectional DC-DC converter with variable input voltage," IEEE Trans. Industrial Electronics, vol. 59, no. 7, pp. 2761-2771, 2012.

[4] F. Zhang and Y. Yan, "Novel forward-flyback hybrid bidirectional DC-DC converter," IEEE Transactions on Industrial Electronics, vol. 56, no. 5, pp. 15781584, 2009.

[5] Gang Chen, Yim-Shu Lee, S. Y. R. Hui, Dehong Xu, and Yousheng Wang, "Actively clamped bidirectional flyback converter," IEEE Transactions on Industrial Electronics, vol. 47, no. 4, pp. 770-779, 2000.

[6] K. Venkatesan, "Current mode controlled bidirectional flyback converter," in proceedings of 20th Annual IEEE Power Electronics Specialists Conference, PESC, pp. 835-842, 1989.

[7] K. Wu, C. de Silva, and W. Dunford, "Stability analysis of isolated bidirectional dual active fullbridge DC-DC converter with triple phase-shift control," IEEE Transactions on Power Electronics, vol. 27, no. 4, pp. 2007-2017, 2012.

[8] R. Naayagi, A. Forsyth, and R. Shuttleworth, "Highpower bidirectional DC-DC converter for aerospace applications," IEEE Transactions on Power Electronics, vol. 27, no. 11, pp. 4366-4379, 2012.

[9] C. Zhao, S. Round, and J. Kolar, "Full-order averaging modelling of zero-voltage-switching phase-shift bidi-rectional DC-DC converters," IET Power Electronics, vol. 3, no. 3, pp. 400-410, 2010.

[10] C. Mi, H. Bai, C. Wang, and S. Gargies, "Operation, design and control of dual $\mathrm{H}$-bridge-based isolated bidirectional DC-DC converter," IET Power Electronics, vol. 1, no. 4, pp. 507-517, 2008.

[11] S. Park, and Y. Song, "An interleaved half-bridge bidirectional DC-DC converter for energy storage system applications," in proceedings of 8th IEEE International Conference on Power Electronics and ECCE Asia (ICPE \& ECCE), pp. 2029-2034, 2011.

[12] B.-R. Lin, C.-L. Huang, and Y.-E. Lee, "Asymmetrical pulse width modulation bidirectional DC-DC converter," IET Power Electronics, vol. 1, no. 3, pp. 336$347,2008$.
[13] F. Peng, H. Li, G.-J. Su, and J. Lawler, "A new ZVS bidirectional DC-DC converter for fuel cell and battery appli-cation," IEEE Transactions on Power Electronics, vol. 19, no. 1, pp. 54-65, 2004.

[14] H. Li, F. Z. Peng, and J. Lawler, "A natural ZVS medium-power bidirectional DC-DC converter with minimum number of devices," IEEE Transactions on Industry Applications, vol. 39, no. 2, pp. 525-535, 2003.

[15] M. Jain, P. Jain, and M. Daniele, "A bidirectional DCDC converter topology for low power application," in proceedings of 28th Annual IEEE Power Electronics Specialists Conference, PESC vol. 1, pp. 804-810, 1997.

[16] João Silvestre, "Half-bridge bidirectional DC-DC Converter for small Electric Vehicle." IEEE International Symposium on Power Electronics, Electrical Drives, Automation and Motion, SPEEDAM, 2008.

[17] Zhiyong Ma, and Renjie Hu. "Zero-voltage-switching condition of isolated-type symmetrical half-bridge bidirectional DC/DC converter." in proceedings of IEEE International Conference on Electrical and Control Engineering (ICECE), 2011.

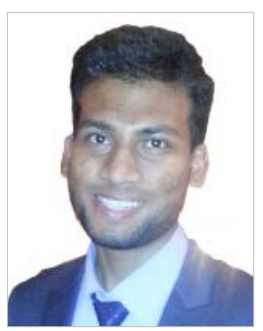

Arsalan Ansari received his B.E. degree in electrical engineering from the Mehran University of Engineering and Technology, Jamshoro, Pakistan, in 2011. He is currently moving towards the completion of his Ph.D. degree in electrical engineering at Hanyang University, Ansan, Korea. He was appointed as a Lecturer with Mehran University of Engineering and Technology. His current research interests include bidirectional DC-DC converters, multilevel inverters and grid-connected renewable energy systems. Mr. Ansari was a recipient of the Scholarship for the Integrated Master and Ph.D. Program by the Government of Pakistan. He was a medalist among his engineering batch.

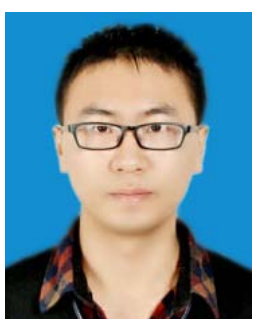

Puyang Cheng received his B.S. degree in Mechanical Engineering and Automation from Wuhan University of Science and Technology, Wuhan, China, in 2013. He is currently working toward the M.S. degree in Electrical Engineering in Hanyang University, Ansan, Korea. His research interests are bidirectional DC/DC converters and power factor correction. 


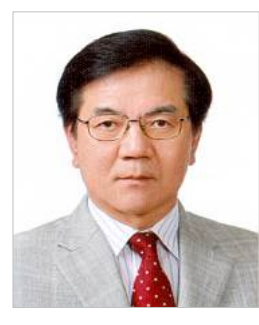

Hee-Jun Kim received the B.S and M.S. degree in electronics engineering from Hanyang University, Seoul, Korea, in 1976 and 1978, respectively, and the Ph.D. degree from Kyushu University, Fukuoka, Japan, in 1986, all in electronics engineering. Since 1987, he has been a Professor with Hanyang University, Ansan, Korea. His current research interests include switching power converters, softswitching techniques, and analog signal processing. Prof. Kim is a senior member of IEEE. 